\title{
Platform transience: changes in Facebook's policies, procedures, and affordances in global electoral politics
}

\section{Bridget Barrett}

Hussman School of Journalism and Media, University of North Carolina at Chapel Hill, United

States,bridget4@live.unc.edu

\section{Daniel Kreiss}

Hussman School of Journalism and Media, University of North Carolina at Chapel Hill, United States,dkreiss@email.unc.edu

Published on 31 Dec 2019 | DOI: 10.14763/2019.4.1446

\begin{abstract}
This paper presents two case studies of Facebook's rapid changes relating to international electoral politics: the “I'm a Voter" affordance and the platform's data and targeting capabilities. The article shows how Facebook changed with respect to its policies, procedures, and affordances, especially given the normative pressure exerted by journalists. Drawing from these case studies, we conceptualise continual and rapid change as "platform transience" and argue that it often arises from external pressure and economic considerations. Platform transience has significant implications for the ability of stakeholders to hold platforms accountable, raises significant issues for electoral fairness, and increases the potential for unequal political information environments.
\end{abstract}

Keywords: Platforms, Electoral politics, Platform change, Platform policies

\section{Article information}

Received: 07 Jul 2019 Reviewed: 17 Nov 2019 Published: 31 Dec 2019

Licence: Creative Commons Attribution 3.0 Germany

Competing interests: The author has declared that no competing interests exist that have influenced the text.

\section{URL:}

http://policyreview.info/articles/analysis/platform-transience-changes-facebooks-policies-proceduresand-affordances-global

Citation: Barrett, B. \& Kreiss, D. (2019). Platform transience: changes in Facebook's policies, procedures, and affordances in global electoral politics. Internet Policy Review, 8(4).

This paper is part of Data-driven elections, a special issue of Internet Policy Review guestedited by Colin J. Bennett and David Lyon.

In September 2018, Facebook announced that it would no longer send its employees to US campaigns as 'embeds' to facilitate their advertising buys and social media presences, a 
programme that was the subject of considerable controversy (Dave, 2018). Months earlier, Facebook rolled out a political and social issues ads verification programme and ad archive in the US and subsequently in other countries, seemingly in response to pressure from lawmakers and journalists to safeguard national elections given increasing evidence of state-sponsored disinformation campaigns (Introducing the Ad Archive Report, 2018; Requiring Authorization and Labeling for Ads with Political Content, 2019; Perez, 2018). At the time of this writing, it is widely reported that Facebook is considering more changes to its political advertising services as part of a contentious US debate and significant shifts by Google and Twitter, including the latter's decision to ban political advertising entirely (Scola, 2019).

These changes are deeply significant for what is a global $\$ 3.6$ billion USD political advertising business on Facebook alone (Kanter, 2018). This is a small percentage of revenue for the global firm, but Facebook is increasingly the central way that candidates around the world get their messages in front of voters. These changes significantly impact the cost structures and efficiencies of political ads, in turn reorienting the actors who create, target, and test them in ways that we will only come to appreciate with time. And, more broadly, the decisions technology firms make shape which voters are exposed to political advertising in the course of electioneering and how they encounter political communications.

The events since the 2016 US presidential election illustrate the rapidity and scale of change in platforms. The fact that platforms continually change is well-cited in the academic literature and referred to in journalistic accounts. Gawer (2014) has an expansive view on how platforms are "evolving organizations" with respect to innovation and competition and technology. There is a very well-documented literature on machine learning, artificial intelligence, and algorithms that stresses continual change (e.g., Ananny, 2016; Beer, 2017; Klinger and Svensson, 2018). Our aim here is to develop an inductive analysis of change at the level of policies, procedures, and affordances through two case studies of Facebook in the context of electoral politics: the ephemerality of the "I'm a Voter" button Facebook rolled out internationally and the data and targeting behind political advertising. We chose these two cases for their relevance to (and normative implications for) data-driven elections but also for the rich array of secondary sources available given that rapid change makes studying platforms and their effects difficult. The "I'm a Voter" button and changes in advertising affordances are unique in that they received significant political and industry media coverage.

We argue that these are two cases of platform transience - a concept we use to describe how platforms change, often dramatically and in short periods of time, in their policies, procedures, and affordances. We use the word 'transience' because it captures the idea that platform change is fast and continual, and as a result they are impermanent and ephemeral in significant ways. As we argue through our analyses of these two case studies, transience can seemingly be spurred by normative pressure from external stakeholders. In our discussion section, we detail the implications of this, alongside other potential mechanisms that underlie platform transience beyond external pressure as a call for future research.

These instances of transience also reveal the widespread failure of Facebook to be transparent about and disclose the workings of an electoral product that the company itself documented was highly impactful in spurring voting. Looking back, for instance, Facebook's blog contains some information on the "I'm a Voter" product and who saw it during the course of elections (“Announcement”, 2008; “Election Day 2012 on Facebook | Facebook Newsroom”, 2012; "Election Day 2014 on Facebook | Facebook Newsroom”, 2014), but they fail to explain which elections in which countries after 2014 the product was used in or even what determined who 
received the notifications. In this context, journalists often struggled to provide the public with details on the product - including screenshots of what the user interface looked like, observed examples of when some people received the reminder and when others didn't, and provided timelines of changes.

As such, these cases also illustrate the implications of platform transience. First, for public representatives such as journalists and policymakers, determining the social and political consequences of platforms to hold them accountable or design policy interventions is especially hard given the pace of change and the lack of transparency that often accompanies them. Second, in the political context, it is likely that better resourced electoral and issue campaigns will be uniquely capable of navigating rapid change, from being able to hire staffers to meet new platform requirements such as verification to having direct access to platforms through dedicated account managers. This raises fundamental issues of electoral fairness. Third, for the users of platforms, transience and the lack of disclosure and accountability increases the likelihood of hidden manipulation and, more broadly, unequal information environments. In the case of "I'm a Voter", entirely unbeknownst to them, some people were the targets of a social pressure experiment designed to spur voting. In the context of data and targeting, some citizens, especially those most politically engaged and ideologically extreme, receive more attention from campaigns based on the underlying technical affordances of platforms.

This paper proceeds in three parts. First, we introduce our case studies around the role of platforms in democratic processes. We then turn to our two case studies to document and analyse platform transience. The paper concludes with a call for future research on other cases of platform transience and details the implications for institutional politics.

\section{PLATFORM TRANSIENCE}

Over the past decade, scholars have grown increasingly attentive to the ways social media platforms - especially those operated by firms such as Facebook, Google, Twitter, Snapchat, and their sister companies and subsidiaries such as YouTube, Instagram, and WhatsApp - serve as infrastructure for much of social life in countries around the world. As Plantin and Punathambekar (2019, p. 2) argue, platforms such as Facebook and Google have:

acquired a scale and indispensability - properties typical of infrastructures - such that living without them shackles social and cultural life. Their reach, market power, and relentless quest for network effects have led companies like Facebook to intervene in and become essential to multiple social and economic sectors.

In this literature, 'platforms' refer simultaneously to technical infrastructures and the corporate organisations that develop, maintain, monetise, and govern them. This means that analysis of platforms entails their infrastructural elements - such as their ubiquity and scale through their technical components - alongside their corporate organisation, policies and procedures, and revenue models. There are a number of veins of literature that analyse various aspects of platforms in this expansive sense. There is an emerging body of work on content moderation, especially in relation to the practices and policies behind what these companies do (Gillespie, 2018) and how this labour is structured and performed (Roberts, 2019). Other research has analysed the economics of platforms and their business models (for a review see de Reuver, Sørensen, and Basole, 2018), governance structures (e.g., Constantinides, Henfridsson, and Parker, 2018; Gorwa, 2019; Helberger, Pierson, and Poell, 2018), and data (e.g., Helmond, 
2015). A body of legal analysis details the regulatory implications of platforms, especially in relation to competition (Pasquale, 2012) and user privacy and data (Balkin, 2016).

We know of only a few research works to-date that have systematically analysed platform companies such as Facebook and Google through the lens of their interactions with other fields. As Van Dijck, Poell, and de Waal (2018) argue, platforms are "programmable digital architecture designed to organize interactions between users -- not just end users but also corporate entities and public bodies...." (ibid., 9) - in the process transforming other fields, which they demonstrate through case studies of news (see also Nielsen and Ganter, 2018), urban transport, health care, and education. Other scholars have analysed how the specific corporate organisation, policies, and business models of platforms in one domain such as politics impact that field (Kreiss and McGregor, 2018; Kreiss and McGregor, 2019).

The ways that platforms shape other fields are especially interesting given the fact that they undergo continual changes. Yet, we lack understanding of the mechanisms and consequences of platform change, particularly in the context of their organisational workings such as policies and procedures, the products they offer, or their affordances. For example, as detailed above, a number of scholars have detailed various aspects of platform change, especially in the context of algorithms (Bucher, 2018) and the versioning of technical products (e.g., Chun, 2016; Karpf, 2012). Platform transience is especially likely to impact actors in other fields given the ways instability likely disrupts institutionalised ways of working and established practices. At the same time, it likely differentially impacts sectors based on the degree to which fields rely on platform products and services, or their comparative autonomy with respect to their economic or technological power.

We are particularly interested in change at the levels of policies, procedures, and affordances. With respect to 'policies', we mean the company-derived rules governing the use of platforms. This is an expansive category that includes everything from terms of service to technical standards. In terms of 'procedures', we mean platforms' ways of working both internally and externally with stakeholders. These include everything from the mechanisms that platform companies have for enforcing policy decisions to how they enable those affected by them to contest decisions. In the political domain, procedures relate to the ways that Facebook political ad sales staffers are vehicles for practitioners to contest policy decisions (such as ads rejected for objectionable content) but also more broadly the organisational and staffing patterns that the company has developed for reviewing content, adjudicating disputes, advising campaigns, developing new political products, etc. We define 'affordances' in terms of previous work as: "what various platforms are actually capable of doing and perceptions of what they enable, along with the actual practices that emerge as people interact with platforms" (Kreiss, Lawrence, and McGregor, 2018, p. 19). The concept of affordances is important because it points to the ways that code structures what people can do on and with platforms, even while platforms invite particular uses through framing what their features are for (see Nagy and Neff, 2015). Policies, procedures, and affordances are likely inter-related in the sense that change in one domain likely affects the others. For example, changes in policies can lead to new procedures, such as when Facebook required the verification of political advertisers which then lead to new registration processes with the platforms. Sometimes, affordances create the need for new policies, such as when the ability to edit headlines of publishers in ads spurred new policies to prevent this from furthering misinformation (see Kreiss and McGregor, 2019). 


\section{THE CASE STUDIES}

To analyse inductively why platforms change and how those changes impact other fields, we developed two case studies relating to Facebook's international electoral efforts. These two case studies are constructed primarily from data collected for a larger comparative project from January to May 2019 on Facebook and Google's involvement in government and elections in five countries: Chile, Germany, India, South Africa, and the United States. We conducted a qualitative content analysis of news coverage about Facebook's work in institutional politics, including industry news outlets such as AdExchanger and Campaigns and Elections. We also analysed material from Facebook's Newsroom, company help centre documents, and company blogs and websites regarding products and services relating to Facebook's work in institutional politics. Finally, we downloaded online resources provided to political actors, such as Facebook's Digital Diplomacy best practices guide and English and German versions of Facebook guides for politicians and governmental actors.

Research into products and services started in the US context. When articles or websites listed additional countries that the services were offered in, we noted this. The creation of our search terms was an iterative and on-going process. After we made lists of policies, products, services, and affordances in English in the US context, we used web services to translate them into Spanish and German and searched for similar material via Google Incognito and a virtual private network (VPN) connection from each relevant country (we chose Express VPN because of its servers in each of the five countries). During the period from January to May 2019 we also used a US-based Facebook Ad Manager to explore the ad targeting interface and create campaigns, which we did not turn on (i.e., no ads were purchased but the campaigns were built out and saved in the platform as inactive or paused). In addition, we created accounts based in Germany and Chile using a VPN connection from those countries.

During this process of passive data collection (see Karpf, 2012), we were able to document Facebook's advertising interface changing as we used it across countries. We also found international coverage of the "I'm a Voter" button and other election reminders which were not clearly documented in Facebook's Newsroom. We then selected these two cases for further analysis and broadened our search outside of the original five countries. While we focus on Facebook in the empirical sections below, in the discussion section we seek to inductively develop an analysis that extends to all platforms in the context of the ways external pressures contribute to platform transience.

\section{THE "I'M A VOTER" BUTTON AND DATA-DRIVEN POLITICS}

In 2008, Facebook released an "It's Election Day" reminder with a button for users to declare "I'm a Voter" to their friends. The "I'm a Voter" button was created to appear for only a day. It was ephemeral by design. The feature included pictures of a few select friends and the total number of the user's friends who self-declared they had voted in the election (Figure 1) (“Announcement: Facebook/ABC News Election 'o8 | Facebook Newsroom", 2008; "Election Day 2012 on Facebook | Facebook Newsroom", 2012). By 2012 this platform feature was accompanied by ways for users to find their polling place, share their political positions, and join groups to debate issues ("Election Day 2012 on Facebook | Facebook Newsroom", 2012). In 2012, Facebook was just gaining many of the features that are now core to its platform including running 'sponsored stories' (also known as native advertising) in users' news feeds (Mullins, 2016; D’Onfro, 2016). 


\section{It's Election Day}

Tell friends you're voting in the 2012 Election and find out where to vote.

\section{Im a Voter}

Find My Polling Place

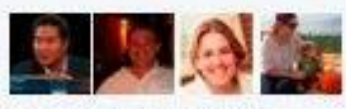

Adam, Adam and 4 others are voters in this election.

Figure 1: 2012, United States (“Election Day 2012 on Facebook | Facebook Newsroom”, 2012)

On Facebook's blog, the company stated that these civic engagement products were born out of a commitment "to encouraging people who use our service to participate in the democratic process" ("Election Day 2012 on Facebook | Facebook Newsroom", 2012). The existence of these tools as early as 2008 speaks to this commitment - Facebook, founded in 2004, began putting resources into engaging its users in politics during the first presidential election after its founding.

While at first glance promoting voter participation might be normatively desirable on democratic grounds, Facebook's attempt to engage citizens in democracy through its platform sparked controversy specifically because of the evidence the company provided that it actually worked. In 2010, Facebook partnered with researchers to test the impact of different versions of the election day reminders in a field experiment. All Facebook users over the age of 18 in the US were assigned to treatment and control groups and voter turnout was later measured through actual voting records (Bond et al., 2012). In the treatment conditions, some users saw the "I'm a Voter" button with a count of how many people had marked themselves as voters (informational group); others saw that count along with pictures of some of their friends who had self-declared themselves as voting (social group) (see Figure 2) (ibid). In the control group, users saw no election reminder at all - the study estimated that 340,000 people turned out to vote due to the election reminders they saw (ibid). These findings are in line with many other studies and experiments showing how social incentives increase voter turnout (Gerber, Green, and Larimer, 2008). This experiment was cited in the campaign industry press as evidence of the power of Facebook in elections (Nyczepir, 2012). 


\section{Today is Election Day What's this? • close \\ Find your polling place on the U.S.

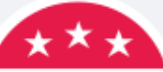 \\ Politics Page and click the "I Voted" button to tell your friends you voted. \\ VOTE \\ $\star \star \star$ \\ I Voted

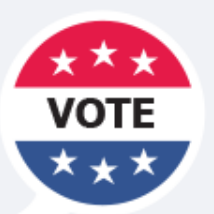 \\ Find your polling place on the U.S. Politics Page and click the "I Voted" button to tell your friends you voted. \\ Jaime Settle, Jason Jones, and 18 other friends have voted. \\ Figure 2: United States Election Day 2010 turn-out study experimental conditions: Informational group and social group (Bond et al., 2012). \\ Questions soon arose in the United States, and later in Europe during the subsequent roll out, about who would benefit from this tool that had the power to increase vote share in potentially consequential ways. Reporting from the United States, Sweden, and the United Kingdom at the time all raised concerns about the questionable ethics of testing different versions of the notification as well as the fact that the company was not clear about what versions were shown to which users and where (Grassegger, 2018; Habblethwaite, 2014; Sifry, 2014). \\ Indeed, there was very little transparency about this tool that evidence suggested could be deeply impactful in electoral contexts. Based on screenshots and write-ups by journalists from nine countries from 2014 to 2016, the "I'm a Voter" button's specific features changed and varied from year to year and country to country. While some countries had the "I'm a Voter" button (Figure 3) others used "share now" instead (Figure 4). The button could be on the right (Figures 3 and 4) or the left side (Figures 5, 6, 8, and 9), and under the option to "share your civic participation' there could be privacy notifications that users were sharing with the public (Figure 4), a prompt to "return to Facebook" (Figure 5), an option for more information (Figures 3, 6, 8 and 9), or no additional prompt at all (Figure 7). This feature was rolled out in Israel and India and was reported by Reuters to have been rolled out worldwide in 2014. The company itself did not verify this given that no Facebook newsroom articles cover the rollout in these countries (Cohen, 2014; Debenedetti, 2014; Kenan, 2015). At the same time, the differences in the design and prompts were not addressed by Facebook in its blog posts, nor were the effects of user interactions with different types of reminders in different countries.}




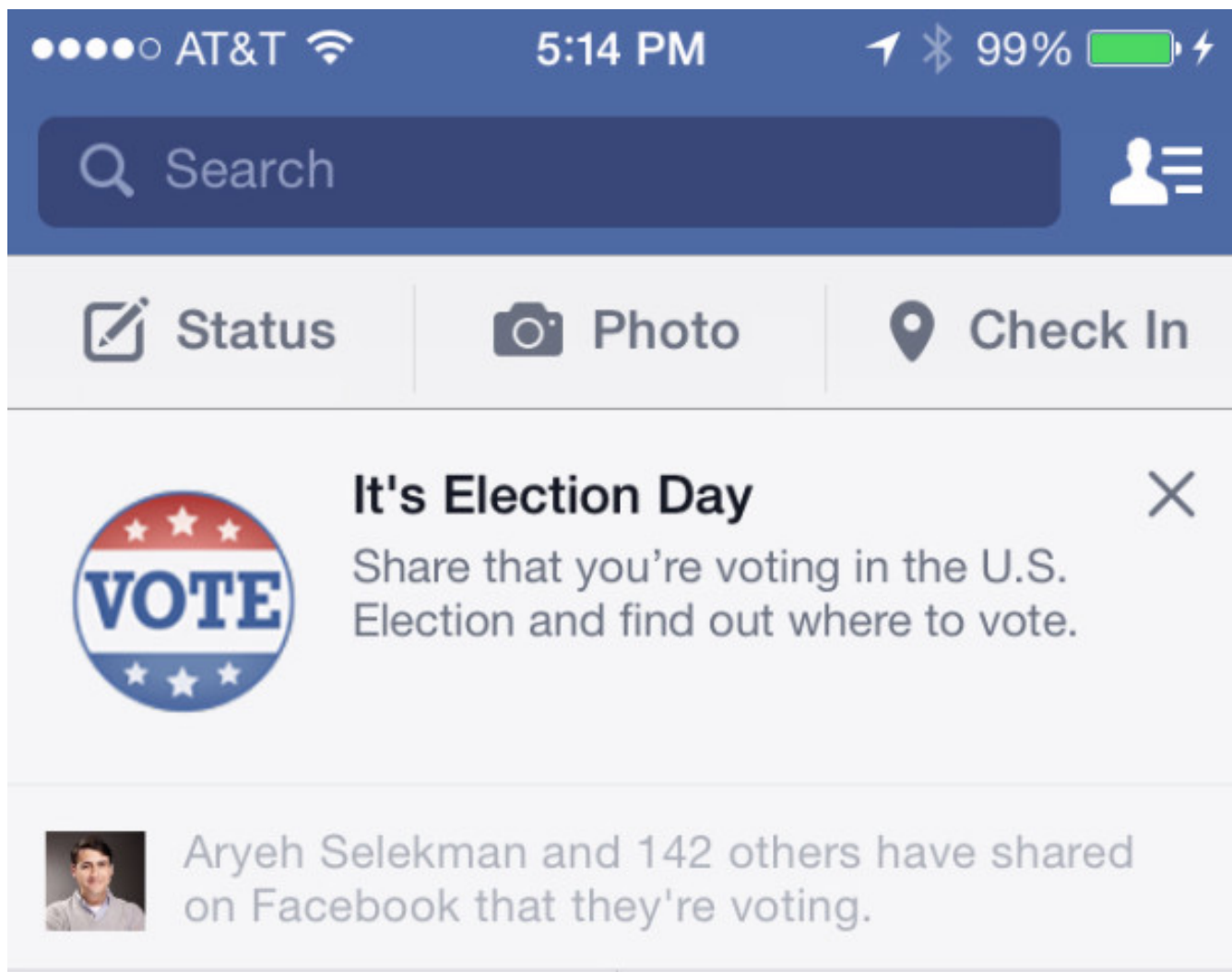

\section{More Information}

\section{I'm a Voter}

Figure 3: 2014, United States ("Election Day 2014 on Facebook | Facebook Newsroom," 2014)

\begin{tabular}{l} 
Q Search \\
\hline Status IO Photo 2 Check In
\end{tabular}

Figure 4: 2014, Scotland (Grassegger, 2018) 


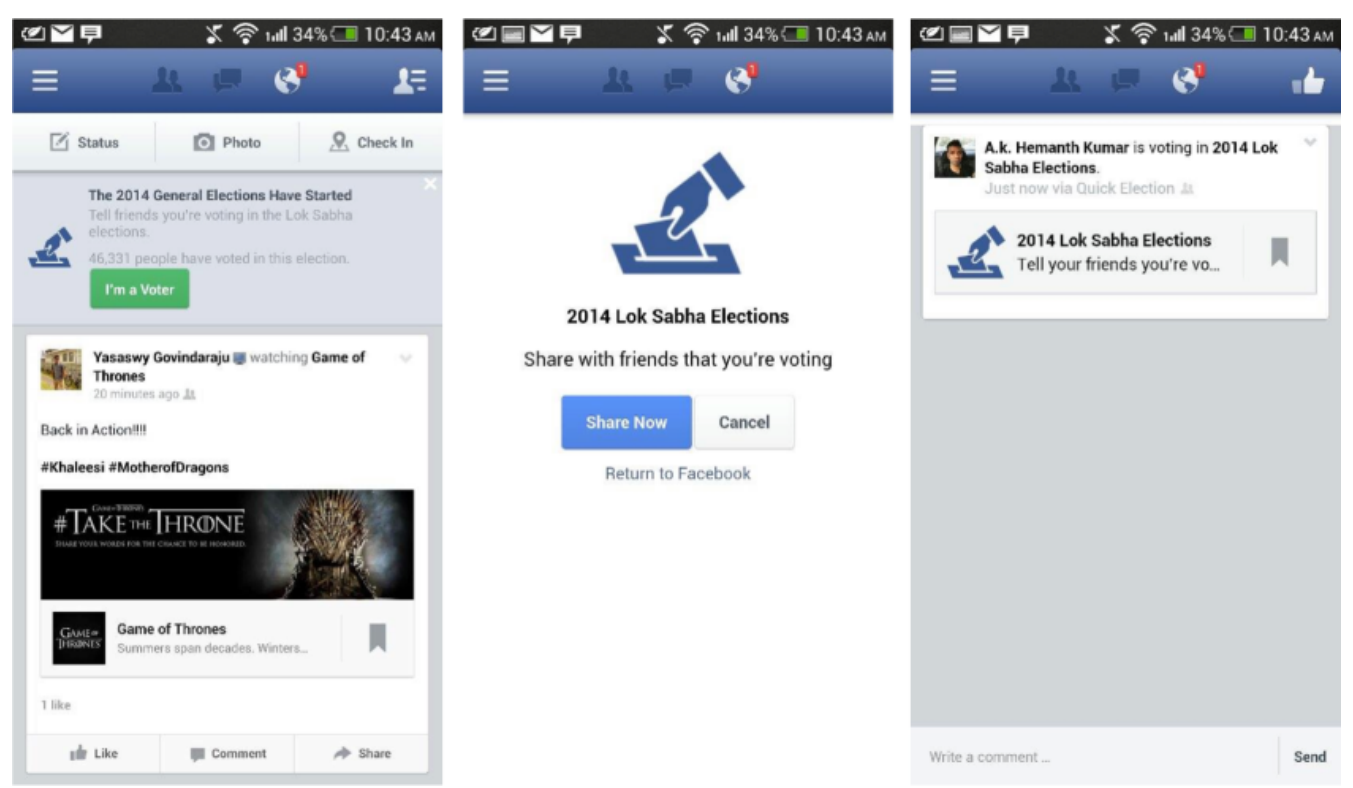

Figure 5: 2014, India (Rodriguez, 2014)

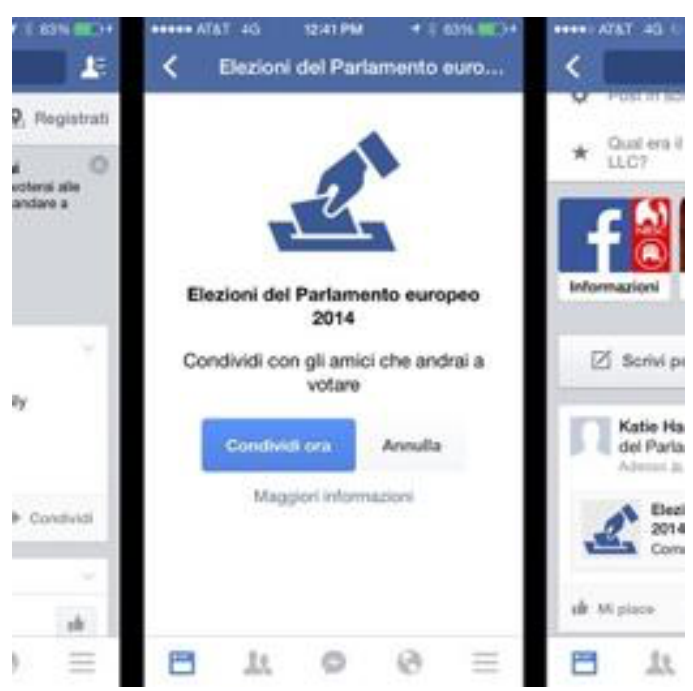

Figure 6: 2014, European Union (Cardinale, 2014)

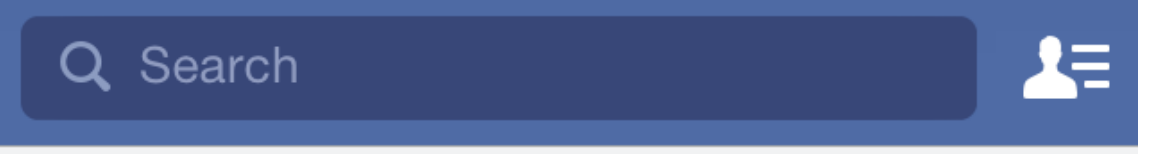

\section{$\llbracket$ Status $\quad 0$ Photo 9 Check In}

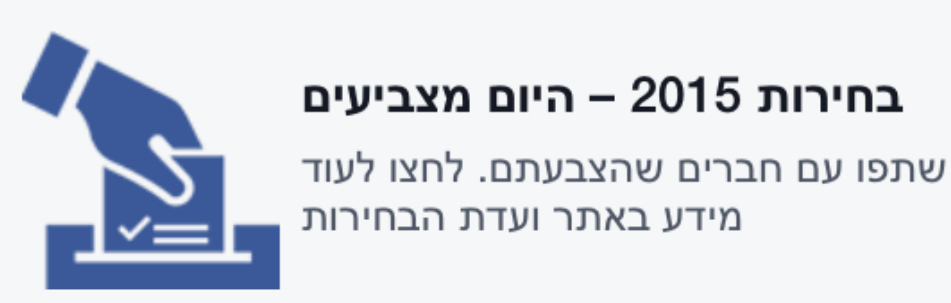

\section{הצבעתי ב -}


Figure 7: Israel, 2015 (Kenan, 2015)

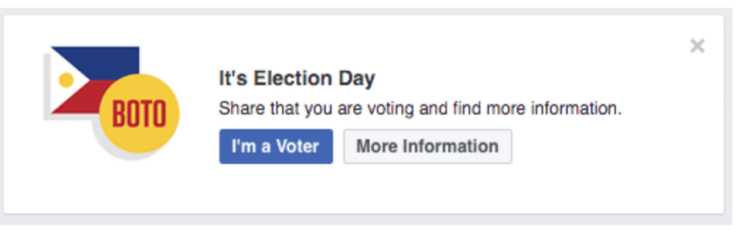

Figure 8: Philippines, 2016 (Lopez, 2016)

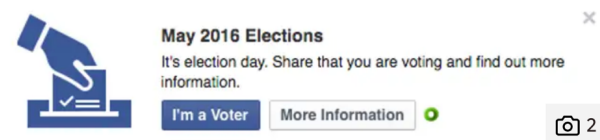

Figure 9: United Kingdom, 2016 (Griffin, 2016)

These undocumented rollouts and differing designs are especially notable given the documented electoral impacts of this tool and the difficulty journalists and researchers faced, and continue to face, in identifying and chronicling the deployment of the tool - both in the moment and especially now, where systematically reconstructing international product rollouts, variation, and change is impossible. In the decade of its development, it was clear that Facebook was not transparent about its electoral product and failed to disclose basic information to electoral stakeholders such as journalists. When the company itself provided information, it raised more questions. Michael Buckly (Facebook's vice president for global business communications) told a Mother Jones reporter that not everyone in the United States saw the feature during the 2012 presidential election due to software bugs, but that these bugs were entirely random (Sifry, 2014). Buckly stated that, in contrast, during the 2014 midterm election "almost every user in the United States over the age of 18 will see the "I Voted" button", although as the author notes these comments were unverifiable and the accuracy of this statement was unclear (ibid.) Indeed, four years later the reach of "I Voted" was still unclear, and observers were still attempting to track the deployment of the tool as best they could. For example, in Iceland a lawyer questioned her friends and believed that not everybody was seeing the vote reminder at the same time, on the same devices, or at all (Grassegger, 2018). Despite her attempts, being outside the company this writer could not determine specific variations of the text, where it appeared on users' feeds, or whether it was being displayed on all operating systems and on older versions of the Facebook app (Grassegger, 2018).

As such, the "I'm a Voter" also reveals the lack of transparency and disclosure by Facebook and the scope of international variation and transience of the platform. It also reveals the role of journalists and other observers in seeking to hold Facebook accountable, and the apparent success they have had at times in compelling platform change. For example, the negative press coverage and pressure from journalists seemingly pushed Facebook to change its policies on running tests on users and publicly declare that it stopped the official testing of the "I'm a Voter" affordance in 2014, at least in the United States (Ferenstein, 2014). Journalistic scrutiny might also have prompted the downplaying of the tool itself. In 2016, for instance, Facebook made changes to the tool in the United States, making it more difficult to access and requiring users to click through multiple menus to share their status as voting (Figure 10) (Grant, 2016). Also in 2016 in the US, Facebook released, and promoted, many more civic engagement tools centred around educating users about political issues and what would be on their ballots instead of the "I'm a Voter" declaration ("Preparing for the US Election 2016 | Facebook Newsroom”, 2016). 


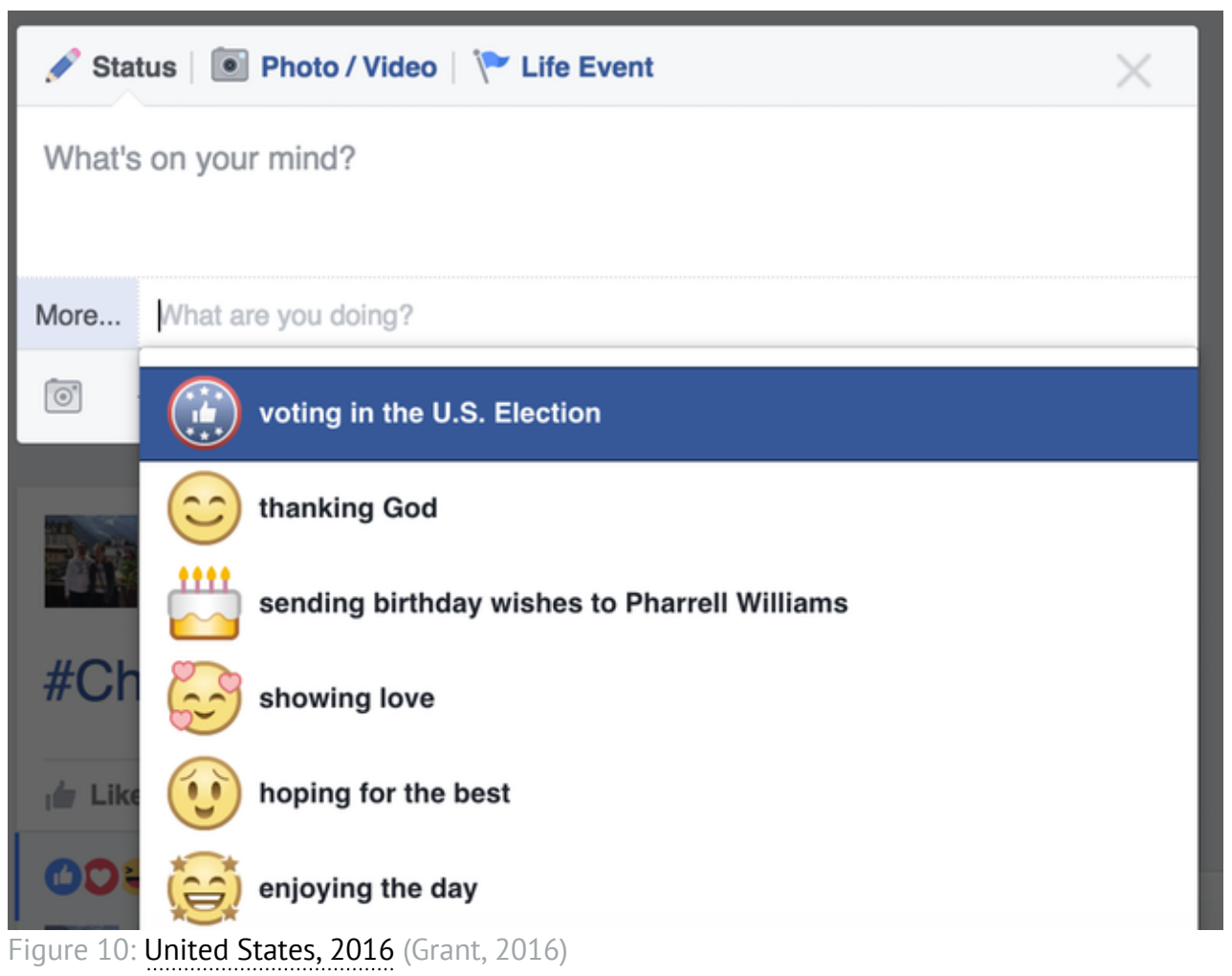

In the end, the extent of changes in the interface for each election, international variations in the tool, who saw election reminders and their effects, the data the company collected, and what will happen during future elections are all unknown. In addition to making it difficult to hold Facebook accountable, these transient affordances impact the political information environment in unknown and potentially deeply problematic ways, as we return to in the discussion section.

\section{POLITICAL MICROTARGETING AND RELATED ADVERTISING AFFORDANCES}

Facebook provides audiences to advertisers to target. Some of these audiences are segmented based on user data such as self-declared age, self-declared employer, or their interests deduced through the websites and Facebook pages they visit. Facebook also offers geolocation targeting of countries, states, cities, and, in the United States, congressional districts (Ads Manager Manage Ads - Campaigns, n.d.). Facebook's behavioural and interest-based targeting includes online or offline behaviour and interests, such as visiting specific locations. The company also offers cross device targeting for almost all of its advertising, meaning that ads are delivered to people on mobile or desktop devices and these profiles are linked so that responses to the advertisements can be attributed back to a single person. In addition, Facebook allows advertisers to load their own "first party" data, including email addresses gathered in stores and website visits online. These first-party audiences can then be targeted on the platform and they can be used as the basis for lookalike audiences.

Ironically, given all the negative attention it has received (Bashyakarla et al., 2019; Chester and Montgomery, 2017), Facebook's interest-based and behavioural targeting is notably limited in the political sphere in the US. The content guidelines and permissible forms of targeting the company allows on its platform are far more restrictive than what an expansive constitutional First Amendment in the United States protects and what political practitioners currently do in other mediums, such as direct mail or door-to-door canvassing. For example, in the United States, when we started our research in spring 2019, Facebook's ad targeting did not have 
“registered Republicans", "registered Democrats", or any party membership categories available to target, nor did it include voting behaviour, such as who voted in the last election (Ads Manager - Manage Ads - Campaigns, n.d.). However, there were ideological targeting options for "US Politics", including "very conservative", "conservative", "moderate", "liberal”, and "very liberal" as well as "likely to engage with political content (conservative)", "moderate", and "liberal" (Figure 11) (ibid).

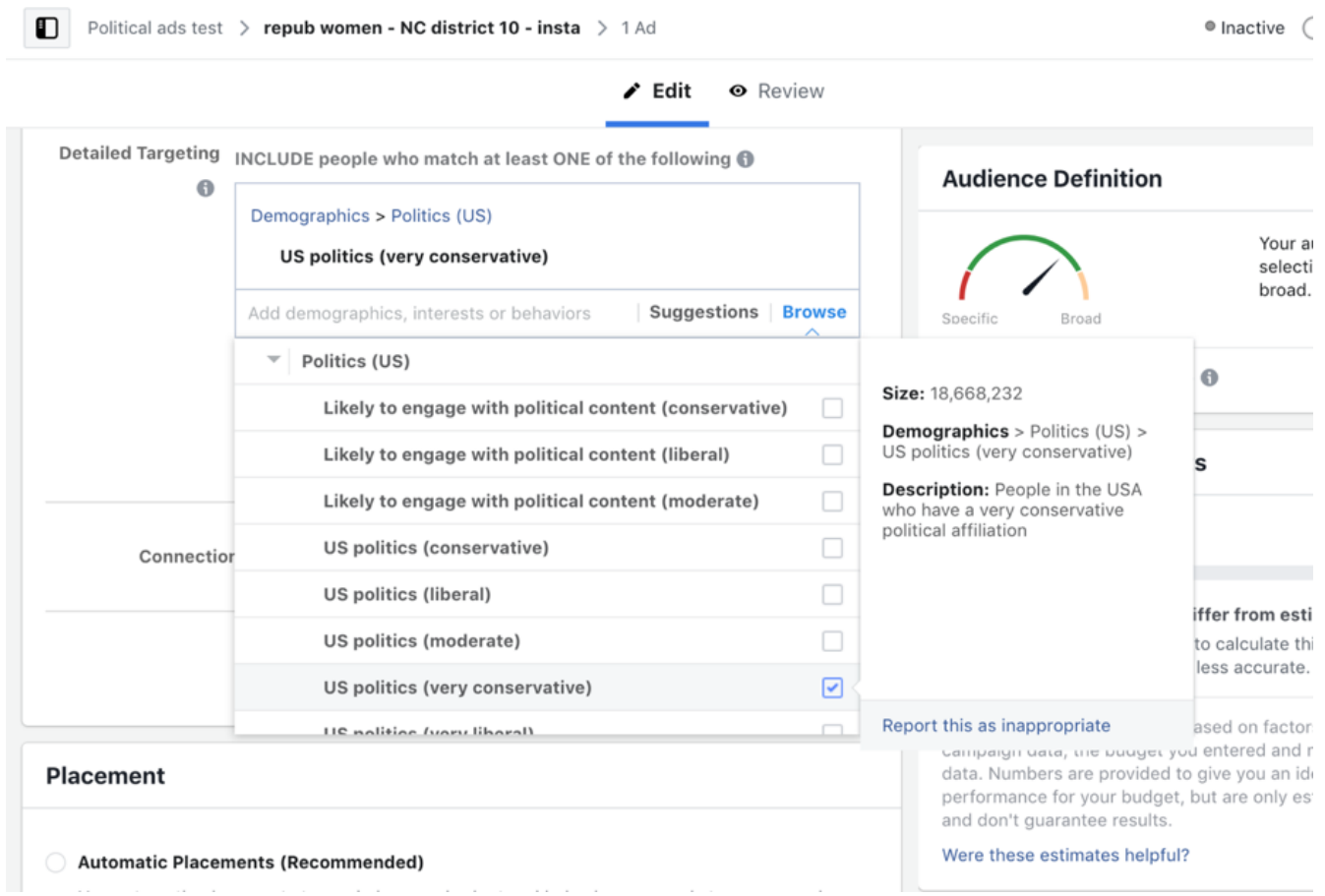

Figure 11: Screenshot from the Facebook ad buying interface, 16 January 2019

These micro-targeting options were also available to use from Facebook Ad Manager accounts made in Chile and Germany (Administrador de anuncios, n.d; Werbeanzeigenmanager, n.d.). The voter targets, however, were oddly specific to the United States - meaning that users in Chile and Germany were being invited to target US citizens. In addition to these political categories, across all the countries we considered advertisers can search for different public figures such as Angela Merkel, Barack Obama, or Sebastian Piñera or political groups such as the Partido Conservador or the Republican Party and target users who "have expressed an interest in or liked pages related to" those people or groups (ibid.). The degree to which any of these categories are used by advertisers is unknown, as is their actual accuracy in predicting voter identification with liberal or conservative ideologies.

In a clear example of the transience of Facebook affordances, these advertising categories changed during the time of us doing the research for this project. On 14 March 2019 Facebook Ad Manager abruptly notified us that the US "very conservative" to "very liberal" political targeting options referenced above were being removed (Figure 12). They were also removed in Germany and Chile. The other advertising targeting capabilities, including general interest in parties and political figures and "likely to engage with political content", were still available. Unlike other well-publicised advertising changes, there were no Facebook blog posts nor major news coverage related to the removal of the five political ad audiences that we could find. If we did not have universes set up targeting these audience segments (but, as detailed above, we did not actively run advertising) we do not think we would have been aware of this change. 


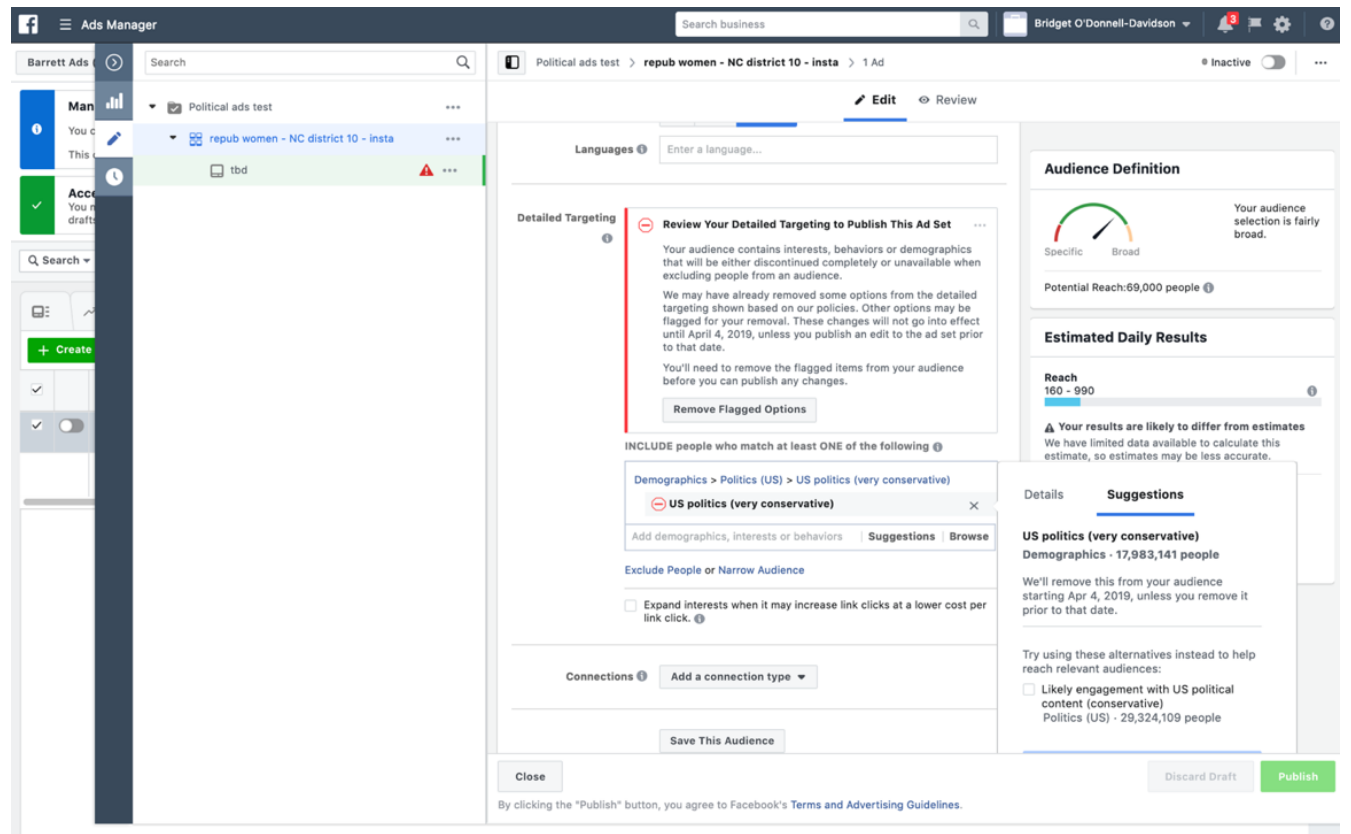

Figure 12: Screenshot from US Facebook ad buying interface, 14 March 2019. Audience segments being removed.

What prompted the removal of these advertising categories is a mystery, although we suspect that it is related to the ongoing and intense scrutiny of Facebook's advertising capabilities given numerous controversies since 2016. For example, in 2017 US media outlet ProPublica published an investigative report on how advertisers could put their ads in front of "jew haters" using Facebook's micro-targeting (Angwin et al., 2017). This audience segment and others were created by an automated system without human review based on what users put on their profiles (ibid.). When enough users declared that they were interested in hating jews, the algorithm accepted this and made them available to advertisers for targeting. Facing public backlash, Facebook removed the audience segments called out by ProPublica (ibid).

These targeting changes have taken place alongside other significant changes in Facebook's political advertising policies, such as the ending of the political 'embed' programme and commissions for its account managers for political ad sales (Dave, 2018). More changes are reportedly on the way as a contentious debate over political advertising in the US takes shape with Twitter banning all political advertising and Google limiting political micro-targeting and more actively vetting political claims (Cox, 2019). Taken together, these amount to significant and sweeping changes to how political advertising can be conducted on the platforms, especially in the United States, and it is unfolding during the course of a presidential election cycle. Again, similar to the "I'm a Voter" affordance, there was little transparency and disclosure from Facebook regarding these changes. Facebook's Help Center, newsroom, and business pages provide no list of retired or new audience segments. We could find no direct documentation from Facebook showing that either the political audiences we saw removed or those covered by ProPublica ever existed.

Normative pressures from external stakeholders such as journalists and the ever-present talk of regulation in the media since 2016 in the US (along with some initial proposed bills such as the Honest Ads Act) likely influenced these changes in Facebook's policies and affordances, although we cannot know for certain. At the same time, Facebook's advertising platform has also undergone a series of changes that impact political advertising likely due to economic incentives. From 2014 to 2017, Facebook introduced carousel ads, lead ads, group ads, and 
created the audience network to allow advertisers to reach Facebook users on other mobile apps ("The Evolution of Facebook Advertising", 2017). At the same time, Facebook removed ad formats ("Full List of Retired Ad Formats", n.d.) as well as numerous metrics ("About metrics being removed”, n.d.). Rationales given for these changes include increasing value to advertisers. For example, Facebook stated that "to help businesses select the most impactful advertising solutions, we've removed the ability to boost certain post types that have proven to generate less engagement and that aren't tied to advertiser objectives" ("Full List of Retired Ad Formats”, n.d.; “About metrics being removed”, n.d.). The company meanwhile removed metrics to replace them with others "that may provide insights that are more actionable" (ibid.).

\section{DISCUSSION}

These cases illustrate how Facebook as a platform undergoes a continual set of changes in its affordances, often without transparency and disclosure, as well as the seeming role of external pressure in driving them. In the case of the shifting international rollout and rollback of the "I'm a Voter" button, it was the stated desire of the company to be socially responsible that put engineering and design resources towards reminding people in democratic countries to vote. Then, it was likely the steady drumbeat of pressure from journalists and observers around the world asking questions about the rollout, implementation, and transparency of the initiative, along with difficult questions for the firm about (unintended) electoral manipulation, that likely led to Facebook scaling back this feature of the platform - culminating with no apparent public announcement of it on the Facebook Newsroom blog during the 2016 US election.

In the case of political data and targeting, ever present policy and affordance ephemerality likely occurs for a mix of reasons relating to external normative pressures and commercial incentives. Clear normative pressure from journalists, as well as the ever-present voices of political representatives and activists in the media, about the role of political advertising in undermining electoral integrity, heightening polarisation, and leading to potential voter manipulation, especially in the wake of Brexit and the 2016 US presidential election, seemingly led to fundamental changes in Facebook's policies and procedures (such as requiring verification for advertisers and building out a political ads database) and affordances (removing the capacity to target based on ideology). At the same time, commercial economic incentives that underlie advertising more broadly have spillover effects in politics, leading to things such as new ad formats and targeting capabilities.

Future research can analyse the contexts within which external pressure compels platform change, and the various stakeholders involved. Due to platform companies increasingly reaching into all areas of social life, the set of stakeholders concerned with their functioning and governance is vast. As Van Dijck, Poell, and De Waal (2018, p. 3) nicely capture, the values of platforms in their architectures and norms often come into conflict with public values in various social domains. As such, platform changes are often the outcomes of a "series of confrontations between different value systems, contesting the balance between private and public interests" (ibid., p. 5). As infrastructure, platforms reconfigure various social sectors in deeply meaningful ways, and bring about conflicts over values and norms relating to privacy, public speech, and electoral fairness, to name a few.

While we can never know for certain, that outside stakeholders seemingly exert considerable pressure on platform companies which can spur change is a logical and plausible conclusion to be drawn from the cases developed here. As these case studies revealed, journalists in particular 
exerted normative scrutiny over Facebook. Platform companies are likely sensitive to negative journalistic attention in part given the press is a representative of public opinion, but also because it can trigger governmental scrutiny, drops in stock price, and user backlash, all of which were in evidence after the 2016 US presidential and Brexit elections. Another category of stakeholder likely particularly relevant in the context of politics are activist groups and partisan and ideological organisations. An example is organisations such as the ACLU, which has led efforts in the US to end certain forms of demographic targeting. These are not the only forms of external pressure from stakeholders. There are likely more expansive sets of regulatory and normative concerns for international platforms that transcend any one recognisable field of activity. These include the regulatory pressures exerted on platform companies by many, and diverse, formal bodies internationally such as the Federal Trade Commission in the United States that has compelled Facebook to alter its data security practices in the country (e.g., Solove and Hartzog, 2014).

At the same time, platforms likely make a host of voluntary decisions about policy, procedures, and affordances that lead to changes towards what they perceive of as desirable social ends. As our case studies demonstrated, seemingly well-intentioned actions by Facebook, such as promoting electoral participation through polling place look-up tools and universal voting reminders, shape how platforms work. These things are normatively defined in relation to a broader cultural and social context. Therefore, change is not simply compelled by pressure, but about actors desiring to be in line with social values, expectations, and ideals. Finally, it is clear from our case studies that there are a number of economic incentives that underlie platform transience. As we detailed, in the past few years Facebook has introduced carousel ads, lead ads, and group ads, new metrics, and targeting affordances - all of which are routinely deployed by political actors.

Future research can analyse additional mechanisms that underlie platform transience. For example, these firms are seemingly isomorphic to one another given that they not only compete in similar domains, they often react to one another's moves and follow one another's decisions around things such as content policy and self-regulation. See, for instance, the cascade of platform decisions to ban the American conspiracist Alex Jones during the summer of 2018 (Hern, 2018) and the recent shifts in political advertising spurred by Twitter's decision to ban all political ads (Cox, 2019). Part of this comes in the context of journalists' ability to exert normative pressure on platforms once a rival makes a significant policy change, but it is also these firms following one another with regard to the normative stakes involved. It is also likely that what certain firms do, or what they are subject to, changes the possibilities for action of other firms. Future research is necessary to analyse when these types of changes occur and why.

Methodologically, scholars can go beyond our initial approach here and comparatively analyse moments of significant change in the context of policies, procedures, and affordances through a process tracing approach, detailing the causal chains that were likely at play in firms' decisionmaking (Collier, 2011) or reconstruct timelines through secondary sources with the aim of comparing transience across platforms and national contexts. And, going forward, scholarship that concerns platforms can make a concerted attempt to document platform changes, even when they are not the primary object of analysis. For example, researchers should record the dates they were accessing pages and take screenshots and save them into the archival Wayback Machine.

Normatively, platform transience begs larger questions relating to public accountability, electoral fairness, and inequality in information environments that have significant implications 
for policy-making. Perhaps the clearest case is how, in each of the instances of transience detailed here, there was shockingly little in the way of public disclosure of these changes to stakeholders and the public and a lack of transparency in terms of what changed, when, and why. Indeed, there was little in the way of a clear justification for any of the changes chronicled here. And, in the case of "I'm a Voter", there was little in the way of disclosure for how this tool actually worked. Given this, it is hard, if not impossible, for journalists, elected officials, researchers, and regulatory agencies to monitor Facebook, and likely all platforms, effectively and hold them accountable for their policies, procedures, and affordances, and those they take away.

The fact that these cases of transience occurred in the context of international institutional politics make them all the more troubling. The fact that journalists had to guess at the implementation of "I'm a Voter" speaks to the magnitude of the potential problem, especially given that it likely shaped electoral participation for thousands, if not millions, of individuals around the world according to Facebook's own data. The firm should be much more proactively forthcoming about the workings of its products and likely and potential changes in its policies, procedures, and affordances, such as alerting journalists and other stakeholders when changes might occur, and provide archival and public documentation of them. Even more, Facebook should develop clear justifications for its decisions and provide opportunities for those with questions to find out information and potentially contest the decisions the firm makes.

At the same time, these cases also highlight how platforms have the power to transform the shape and the dynamics of other fields. In the political domain, this raises issues related to electoral fairness. Facebook's 7 million advertisers (Flynn, 2019), including political campaigns, have to navigate a rapidly changing advertising environment with limited notice and often no records of transient features of the platforms that impact the voters they can reach, how they can reach them, and the cost of doing so. Through established relationships with platform companies, larger, higher-spending political advertisers may have forewarning of changes and help understanding them, thus granting them unique advantages over their smaller rivals (Kreiss and McGregor, 2019). Meanwhile, larger campaigns and consultancies with many staffers are likely better able to perceive and respond to changes in platforms than their smaller counterparts. For example, new verification requirements likely benefited consultancies with the infrastructure to handle the process for their clients, and changes in content moderation policies likely benefit large firms that can get a hearing for such things as disapprovals (ibid.). How transience impacts other fields should be a key area of research going forward.

At the core of all of the changes documented here is the likelihood that platforms can create fundamentally unequal information environments. The fact that not all citizens of any given country likely saw the same social cues to vote means that some have powerful prompts to turnout, and therefore some citizens' voices are disproportionately heard. With respect to data and targeting, the lack of transparency around key changes in things such as the targeting of political ads means that citizens cannot hope to know why they are seeing the messages they are - and journalists and regulators cannot answer questions regarding who receives political messages driving them to the polls, or keeping them home with respect to demobilising ads. For regulators, establishing rules in a rapidly changing platform ecosystem without transparency into what is changing, why, and when creates a unique challenge. Facebook's ad transparency database simply underscores this point - with ongoing changes in targeting and the platform's own algorithms and only the crudest company-derived categories of ad reach available, there is little in the way of transparency regarding the ways that political content is being delivered, and political attention structured, by campaigns and the platform itself. 


\section{CONCLUSION}

While all of our empirical cases concerned Facebook, transience is likely a feature of all platforms and external pressure from stakeholders likely affects all platforms. As this paper detailed, particularly concerning is the lack of clear public disclosure and transparency in Facebook's changes in its platform, which potentially impacted what millions of people around the world saw in terms of social pressure to vote and how campaigns could contact voters. This raises a deeply troubling set of normative issues in the context of institutional politics, from unequal information environments to the fairness of electoral competition. The challenges that we had as researchers documenting platform changes and their implications, and that observers around the world encountered as well, underscores how difficult crafting effective policy responses to platform power will be, unless we compel stronger public disclosure and accountability mechanisms on these firms.

\section{DISCLOSURE}

When filing the final version of this text, the authors declared to have contributed equally to this paper. 


\section{REFERENCES}

About metrics being removed. (n.d.). Retrieved June 25, 2019, from Facebook Ads Help Center website: https://www.facebook.com/business/help/metrics-removal

Administrador de anuncios - Manage Ads (n.d.). Retrieved March 15, 2019, from https://business.facebook.com/adsmanager/manage/adsets/edit

Ads Manager - Manage Ads - Campaigns. (n.d.). Retrieved March 15, 2019, from https://business.facebook.com/adsmanager/manage/campaigns?

Ananny, M. (2016). Toward an ethics of algorithms: Convening, observation, probability, and timeliness. Science, Technology, \& Human Values, 41(1), 93-117.

https://doi.org/10.1177/0162243915606523

Angwin, J., Varner, M., Tobin, A. (2017, September 14). Facebook Enabled Advertisers to Reach 'Jew Haters'. ProPublica. https://www.propublica.org/article/facebook-enabled-advertisersto-reach-jew-haters

Announcement: Facebook/ABC News Election 'o8 (2008, January 4). Facebook Newsroom. Retrieved June 25, 2019, from https://newsroom.fb.com/news/2008/o1/announcementfacebookabc-news-election-o8/

Balkin, J. M. (2016). Information fiduciaries and the first amendment. UC Davis Law Review, 49(4), 1183-1234. Retrieved from https://lawreview.law.ucdavis.edu/issues/49/4/Lecture/494_Balkin.pdf

Bashyakarla, V., Hankey, S. Macintyre, A., Rennó, R., \& Wright, G. (2019). Personal Data: Political Persuasion. Inside the Influence Industry. How it works. Berlin: Tactical Tech. Retrieved from https://tacticaltech.org/media/Personal-Data-Political-Persuasion-How-itworks.pdf

Beer, D. (2017). The social power of algorithms. Information, Communication \& Society, 2O(1), 1-13. https://doi.org/10.1080/1369118X.2016.1216147

Bond, R. M., Fariss, C. J., Jones, J. J., Kramer, A. D. I., Marlow, C., Settle, J. E., \& Fowler, J. H. (2012). A 61-million-person experiment in social influence and political mobilization. Nature, 489(7415), 295-298. https://doi.org/10.1038/nature11421

Bucher, T. (2018). If... then: Algorithmic power and politics. New York: Oxford University Press. https://doi.org/10.1093/oso/9780190493028.001.0001

Cardinale, R. (2014, May 25). Elezioni Europee 2014: Il pulsante Facebook e il Google Doodle [European Elections 2014: Facebook button and Google Doodle]. Retrieved July 3, 2019, from Be Social Be Honest website:

http://www.besocialbehonest.it/2014/o5/25/elezioni-europee-2014-il-pulsante-facebook-e-il-g oogle-doodle/

Chester, J., \& Montgomery, K. C. (2017). The role of digital marketing in political campaigns. Internet Policy Review, 6(4). https://doi.org/10.14763/2017.4.773

Chun, W. H. K. (2016). Updating to Remain the Same: Habitual New Media. Cambridge, MA: The MIT Press. 
Cohen, D. (2014, April 10). India Facebook Users Can Declare, 'I'm A Voter.' Adweek. Retrieved June 25, 2019, from https://www.adweek.com/digital/india-im-a-voter/

Collier, D. (2011). Understanding process tracing. PS: Political Science \& Politics, 44(4), 823-830. https://doi.org/10.1017/s1049096511001429

Constantinides, P., Henfridsson, O., \& Parker, G. G. (2018). Introduction-Platforms and Infrastructures in the Digital Age. Information Systems Research, 29(2), 381-400.

https://doi.org/10.1287/isre.2018.0794

Cox, K. (2019, November 22). Google Bans Microtargeting and "False Claims" in Political Ads." ArsTechnica. Retrieved December 9, 2017 from https://arstechnica.com/techpolicy/2019/11/google-bans-microtargeting-and-false-claims-in-political-ads/

Dave, P. (2018, September 21). Facebook to drop on-site support for political campaigns." Reuters. Retrieved July 10, 2019 from: https://www.reuters.com/article/us-facebook-electionusa/facebook-to-drop-on-site-support-for-political-campaigns-idUSKCN1M101Q

Debenedetti, G. (2014, May 19). Facebook to roll out "I'm a Voter" feature worldwide. Reuters. Retrieved from https://www.reuters.com/article/us-usa-facebook-votersidUSBREA4IOQQ20140519

de Reuver, M., Sørensen, C., \& Basole, R. C. (2018). The digital platform: a research agenda. Journal of Information Technology, 33(2), 124-135. https://doi.org/10.1057/s41265-016oo33-3

D’Onfro, J. (2016, February 4). Facebook looked completely different 12 years ago - here's what's changed over the years. Business Insider. Retrieved June 25, 2019, from https://www.businessinsider.com/what-facebook-used-to-look-like-12-year-ago-2016-1

Election Day 2012 on Facebook. (2012, November 6). Facebook Newsroom. Retrieved June 22, 2019, from https://newsroom.fb.com/news/2012/11/election-day-2012-on-facebook/

Election Day 2014 on Facebook. (2014, November 4). Facebook Newsroom. Retrieved July 3, 2019, from https://newsroom.fb.com/news/2014/11/election-day-2014-on-facebook/

American Civil Liberties Union. (2019, March 9). Facebook agrees to sweeping reforms to curb discriminatory ad targeting practices [Press release]. Retrieved from:

https://www.aclu.org/press-releases/facebook-agrees-sweepingreforms-curb-discriminatory-ad-targeting-practices

Ferenstein, G. (2014, November 2). After being criticized for its experiments, Facebook pulls the plug on a useful one. VentureBeat. Retrieved July 5, 2019 from https://venturebeat.com/2014/11/o2/facebook-is-so-scaredof-the-press-theyve-stopped-innovating/

Flynn, K. (2019, January 30). Cheatsheet: Facebook now has $7 \mathrm{~m}$ advertisers. Digiday. Retrieved July 6, 2019, from https://digiday.com/marketing/facebook-earnings-q4-2018/

Full List of Retired Ad Formats. (n.d.). Retrieved June 25, 2019, from Facebook Ads Help Center website: https://www.facebook.com/business/help/420508368346352

Gerber, A. S., Green, D. P., \& Larimer, C. W. (2008). Social Pressure and Voter Turnout: 
Evidence from a Large-Scale Field Experiment. American Political Science Review, 102(1), 33-48. https://doi.org/10.1017/Sooo305540808009X

Gillespie, T. (2018). Custodians of the Internet: Platforms, content moderation, and the hidden decisions that shape social media. New Haven: Yale University Press.

Gorwa, R. (2019). What is platform governance?. Information, Communication \& Society, 22(6),

854-871. https://doi.org/10.1080/1369118X.2019.1573914

Grant, M. (2016, November 8). How To Show That You Voted On Facebook. Bustle. Retrieved June 25, 2019, from https://www.bustle.com/articles/193836-how-to-use-the-voting-in-theus-election-status-on-facebook-because-you-deserve-a

Grassegger, H. (2018, April 15). Facebook says its 'voter button' is good for turnout. But should the tech giant be nudging us at all? The Guardian. Retrieved June 25, 2019 from https://www.theguardian.com/technology/2018/apr/15/facebook-says-itvoter-button-is-good-for-turn-but-should-the-tech-giant-be-nudging-us-at-all

Griffin, A. (2016, May 5). How Facebook is manipulating you to vote. The Independent. Retrieved July 9, 2019 from https://www.independent.co.uk/life-style/gadgets-andtech/news/uk-elections-2016-how-facebook-is-manipulating-you-to-vote-a7015196.html

Habblethwaite, C. (2014, May 22). Why does Facebook want you to vote? BBC. Retrieved from https://www.bbc.com/news/blogs-trending-27518691

Helberger, N., Pierson, J., \& Poell, T. (2018). Governing online platforms: From contested to cooperative responsibility. The Information Society, 34(1), 1-14.

https://doi.org/10.1080/01972243.2017.1391913

Helmond, A. (2015). The platformization of the web: Making web data platform ready. Social Media + Society, 1(2). https://doi.org/10.1177/2056305115603080

Hern, A. (2018, August 6). Facebook, Apple, YouTube and Spotify Ban Infowars' Alex Jones. The Guardian. Retrieved July 8, 2019 from

https://www.theguardian.com/technology/2018/aug/o6/apple-removes-podcasts-infowars-ale $\mathrm{x}$-jones

Introducing the Ad Archive Report: A Closer Look at Political and Issue Ads. (2018, October 23). Facebook Newsroom. Retrieved July 7, 2019, from

https://newsroom.fb.com/news/2018/10/ad-archive-report/

Kanter, J. (2018, May 25). Facebook Gave 4 Reasons Why It's Ready to Lose Money and Credibility to Continue Running Political Adverts. Business Insider. Retrieved July 9, 2019 https://techcrunch.com/2018/o4/23/facebooks-new-authorization-process-for-politicalads-goes-live-in-the-u-s/

Karpf, D. (2012). Social science research methods in Internet time. Information, communication \& society, 15(5), 639-661. https://doi.org/10.1080/1369118X.2012.665468

Kenan, E. (2015, February 19). Facebook to add "I voted" button for Israeli elections. Ynetnews. 
Retrieved June 25, 2019, from https://www.ynetnews.com/articles/o,7340,L-4628546,oo.html

Klinger, U., \& Svensson, J. (2018). The end of media logics? On algorithms and agency. New Media \& Society, 2O(12), 4653-4670. https://doi.org/10.1177/1461444818779750

Kreiss, D., Lawrence, R. G., \& McGregor, S. C. (2018). In their own words: Political practitioner accounts of candidates, audiences, affordances, genres, and timing in strategic social media use. Political communication, 35(1), 8-31. https://doi.org/10.1080/10584609.2017.1334727

Kreiss, D., \& McGregor, S. C. (2018). Technology firms shape political communication: The work of Microsoft, Facebook, Twitter, and Google with campaigns during the 2016 US presidential cycle. Political Communication, 35(2), 155-177.

https://doi.org/10.1080/10584609.2017.1364814

Lopez, M. (2016, May 8). Facebook announces 'I'm a voter' button ahead of 2016 Philippine elections. GadgetMatch. Retrieved July 3, 2019 from

https://www.gadgetmatch.com/facebook-election-day-button-2016-philippine-elections/

Mullins, J. (2016, February 4). This Is How Facebook Has Changed Over the Years. E! Online. Retrieved June 25, 2019, from https://www.eonline.com/news/736769/this-is-how-facebookhas-changed-over-the-past-12-years

Nagy, P., \& Neff, G. (2015). Imagined affordance: Reconstructing a keyword for communication theory. Social Media+ Society, 1(2). https://doi.org/10.1177/2056305115603385

Nielsen, K. R., \& Ganter, S. A. (2018). Dealing with digital intermediaries: A case study of the relations between publishers and platforms. New media \& society, 20(4), 1600-1617.

https://doi.org/10.1177/1461444817701318

Nyczepir, D. (2012, September 12). Study: GOTV messages on social media increase turnout. Retrieved July 3, 2019, from https://www.campaignsandelections.com/campaigninsider/study-gotv-messages-on-social-media-increase-turnout

Perez, S. (2018, April 23). Facebook's New Authorization Process for Political Ads Goes Live in the U.S. TechCrunch. Retrieved from https://techcrunch.com/2018/04/23/facebooks-newauthorization-process-for-political-ads-goes-live-in-the-u-s/

Plantin, J. C., \& Punathambekar, A. (2019). Digital media infrastructures: pipes, platforms, and politics. Media, Culture \& Society, 41(2), 163-174. https://doi.org/10.1177/0163443718818376

Plantin, J.-C., Lagoze, C., Edwards, P. N., \& Sandvig, C. (2018). Infrastructure studies meet platform studies in the age of Google and Facebook. New Media \& Society, 20(1), 293-310. https://doi.org/10.1177/1461444816661553

Preparing for the US Election 2016. (2016, October 28). Facebook Newsroom. Retrieved June 25, 2019, from https://newsroom.fb.com/news/2016/10/preparing-for-the-us-election-2016/

Requiring Authorization and Labeling for Ads with Political Content. (2019, May 24). Facebook Business. Retrieved July 7, 2019, from https://www.facebook.com/business/news/requiringauthorization-and-labeling-for-ads-with-political-content

Roberts, S. T. (2019). Behind the Screen: Content Moderation in the Shadows of Social Media. New Haven: Yale University Press. 
Rodriguez, S. (2014, May 20). Facebook expands "I'm a Voter" feature to international users. Los Angeles Times. Retrieved July 9, 2019 from

https://www.latimes.com/business/technology/la-fi-tn-facebook-im-a-voter-international-201 40520-story.html

Scola, N. (2019, November 7). Facebook considering limits on targeted campaign ads. Politico. Retrieved from: https://www.politico.com/news/2019/11/o7/facebook-targeted-campaign-adlimits-067550

Sifry, M. (2014, October 31). Facebook wants you to vote on Tuesday. Here's how it messed with your feed in 2012. Mother Jones. Retrieved July 3, 2019, from

https://www.motherjones.com/politics/2014/10/can-

voting-facebook-button-improve-voter-turnout/

Solove, D. J., \& Hartzog, W. (2014). The FTC and the new common law of privacy. Columbia Law Review, 114(3), 583-676. Retrieved from https://columbialawreview.org/content/the-ftcand-the-new-common-law-of-privacy/

The Evolution of Facebook Advertising (Timeline of Facebook Advertising). (2017, March 7). Retrieved June 25, 2019, from Bamboo website: https://growwithbamboo.com/blog/theevolution-of-facebook-advertising/

van Dijck, J., Poell, T., \& de Waal, M. (2018). The platform society: Public values in a connective world. New York: Oxford University Press.

https://doi.org/10.1093/oso/9780190889760.001.0001

Werbeanzeigenmnanager - Manage Ads (n.d.). Retrieved March 15, 2019, from https://business.facebook.com/adsmanager/manage/campaigns

Zelm, A. (2018, July 17). Facebook Reach in 2018: How Many Fans Actually See Your Posts? [Blog post] Retrieved July 8, 2019, from https://www.kunocreative.com/blog/facebook-reachin-2018 